Polymer Journal, Vol. 38, No. 9, pp. 912-919 (2006)

(C) 2006 The Society of Polymer Science, Japan

\title{
Helicity Induction on a Poly(phenylacetylene) Derivative Bearing a Sulfonic Acid Pendant with Chiral Amines and Memory of the Macromolecular Helicity in Dimethyl Sulfoxide
}

\author{
Takashi Hasegawa, Katsuhiro MAEDA, Hiroyuki Ishiguro, and Eiji Yashima ${ }^{\dagger}$ \\ Department of Molecular Design and Engineering, Graduate School of Engineering, \\ Nagoya University, Chikusa-ku, Nagoya 464-8603, Japan
}

(Received May 10, 2006; Accepted May 23, 2006; Published July 28, 2006)

\begin{abstract}
A stereoregular poly(phenylacetylene) derivative bearing a sulfonic acid residue (poly-1) as the pendant was found to form a predominantly one-handed helix upon complexation with various chiral amines through noncovalent acid-base interactions in dimethyl sulfoxide (DMSO). In sharp contrast to analogous poly(phenylacetylene)s bearing relatively weak carboxy and phosphonic acid residues as the pendants, the poly-1-amine complexes exhibited a weak induced circular dichroism (ICD) in the UV-visible region of the polymer backbone. However, in the presence of a strong acid, such as $p$-toluenesulfonic acid (TosOH), the ICD intensity significantly increased, resulting from a favorable ion pair formation between the sulfonic acid residues of the poly-1 and chiral amines, leading to an increase in the helical sense excess of poly-1. Moreover, the macromolecular helicity of poly-1 induced by chiral amines in the presence of TosOH was "memorized" after the chiral amines and their salts were completely removed and replaced with an achiral diamine, i.e., ethylene diamine, in DMSO, while no memory effect was observed for a helical poly-1 induced by the same chiral amines in the absence of TosOH. [doi:10.1295/polymj.PJ2006028]

KEY WORDS Induced Circular Dichroism / Helicity Induction / Helix / Poly(phenylacetylene) / Memory /
\end{abstract}

Constructing artificial helical polymers ${ }^{1-13}$ and oligomers (foldamers) $)^{14-18}$ or supramolecular helical assemblies ${ }^{19-25}$ with controlled helicity has attracted significant interest in recent years in the fields of polymer and supramolecular chemistry because of their potential applications for novel chiral materials. In a series of our studies, we reported the helicity induction in optically inactive, cis-transoidal poly((4-carboxyphenyl)acetylene) (PCPA), ${ }^{26-29}$ poly((4-phosphonophenyl)acetylene) (PPPA), ${ }^{30-32}$ and poly(ethyl(4-ethynylphenyl)phosphonate) (PEPPA) ${ }^{30,31,33,34}$ (Figure 1) with chiral amines in dimethyl sulfoxide (DMSO) and some amino acids in water. The complexes exhibited an induced circular dichroism (ICD) in the UV-visible region of the polymer backbones due to the predominantly one-handed helical structures. PPPA and PEPPA with phosphonic acid residues more acidic than the carboxy groups of PCPA responded to chiral amines more efficiently than PCPA and exhibited more intense ICDs. ${ }^{29,31}$ Moreover, the induced macromolecular helicity in PCPA upon complexation with optically active amines can be "memorized" after the optically active amines are completely replaced with achiral monoamines and amino alcohols. ${ }^{35-38}$ The mechanism of the helicity induction and the memory of the helical chirality of PCPA have been investigated in detail by UV-visible, CD, and IR spectroscopies, and the following conclusions were drawn: 1) the ion pair formation between the carboxy groups of PCPA and chiral amines is essential for the helicity induction in one-handedness excess, and 2) the electrostatic repulsion between the neighboring carboxylate groups of PCPA arising from the dissociation of the ion pairs plays a central role for the macromolecular hel-

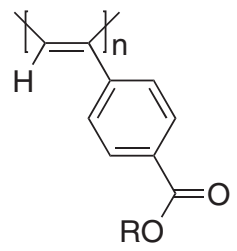

PCPA

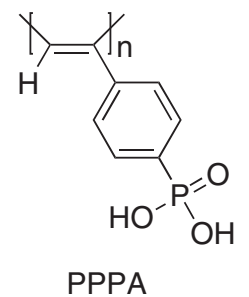

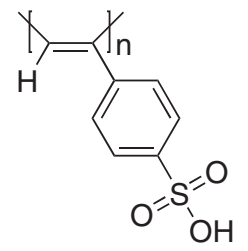

poly-1

Figure 1. Structures of poly(phenylacetylene)s bearing acidic functional groups as the pendants.

${ }^{\dagger}$ To whom correspondence should be addressed (Tel: +81-52-789-4495, Fax: +81-52-789-3185, E-mail: yashima@apchem.nagoya-u.ac.jp). 
icity memory of PCPA in DMSO. ${ }^{36}$ Recently, a similar macromolecular helicity memory has also been attained in PPPA and PEPPA. However, achiral diamines or oligoamines instead of achiral monoamines were indispensable for the memory of the macromolecular helicity in PPPA and PEPPA as chaperoning molecules. ${ }^{31}$

In this study, we investigated if a similar helicity induction and memory of the helicity could be possible for an analogous cis-transoidal poly(phenylacetylene) bearing a sulfonic acid residue (poly-1) as the pendant (Figure 1) in DMSO. The results are compared with the previously reported helicity induction and memory effect of PCPA, PPPA, and PEPPA. Poly-1 has a more acidic sulfonic acid group than the carboxy group of PCPA and phosphonic acid residues of PPPA and PEPPA, so that helicity induction may more efficiently occur in poly-1, resulting in more intense ICDs in its polymer backbone region. Recently, we systematically investigated the helicity induction in cis-transoidal poly(phenylacetylene)s bearing various acidic functional groups as the pendants (PCPA, PPPA, PEPPA, and poly-1) (Figure 1) in the presence of optically active amino acids and amines in water using CD spectroscopy and potentiometric $\mathrm{pH}$ titrations in order to propose the helicity induction mechanism in the polyelectrolytes in water. ${ }^{29}$ However, the helicity induction in poly-1 and its macromolecular helicity memory in organic solvents have not yet been reported.

\section{EXPERIMENTAL}

\section{Materials}

Anhydrous DMSO (water content $<0.005 \%$ ) was purchased from Aldrich and stored under nitrogen. $(R)$ - and $(S)$-1-(1-Naphthyl)ethylamine $((R)-2,(S)-2)$ and $(R)$-1-phenylethylamine $((R)-3)$ were kindly supplied from Yamakawa Chemical (Tokyo, Japan), distilled under reduced pressure. $(S)-(+)$-sec-Butylamine $((S)-5)$ was obtained from Aldrich and distilled under reduced pressure. $(1 R, 2 S)$-Norephedrine $((1 R, 2 S)-\mathbf{8})$ was obtained from Aldrich and used as received. 2Aminoethanol (13) (Kishida, Osaka, Japan) and ethylenediamine (15) (Tokyo Kasei (TCI), Tokyo, Japan) were dried over calcium oxide and potassium hydroxide, respectively, and distilled under reduced pressure. $n$-Butylamine (14) (Kishida) was dried over calcium hydride and distilled under nitrogen. These amines were stored under nitrogen. Other achiral amines were available from Aldrich or TCI. $p$-Toluenesulfonic acid (TosOH) was purchased from TCI and used as received.

Cis-transoidal poly-1 was prepared by polymerization of ammonium 4-ethynylbenzenesulfonate with
$\left[\mathrm{Rh}(\operatorname{cod})_{2}\right] \mathrm{BF}_{4}(\operatorname{cod}=$ cyclooctadiene $)$ in water at $30{ }^{\circ} \mathrm{C}$, followed by treatment with $2 \mathrm{~N} \mathrm{HCl}$ aq $(86 \%$ yield) according to the previously reported method. ${ }^{29}$ The stereoregularity of the poly-1 was confirmed to be a highly cis-transoidal by NMR spectroscopy. ${ }^{39-43}$ The number-average molecular weight $\left(M_{\mathrm{n}}\right)$ and molecular weight distribution $\left(M_{\mathrm{w}} / M_{\mathrm{n}}\right)$ of poly-1 were $9.5 \times 10^{4}$ and 5.6, respectively, as determined by sizeexclusion chromatography (SEC) using poly(ethylene oxide) and poly(ethylene glycol) standards in wateracetonitrile $(4 / 1, \mathrm{v} / \mathrm{v})$ containing $0.16 \mathrm{M}$ sodium nitrate as the eluent. ${ }^{29}$

Spectroscopic data of poly-1: IR (KBr, v): 1168 and $1036(\mathrm{~S}=\mathrm{O}) \mathrm{cm}^{-1} .{ }^{1} \mathrm{H}$ NMR $\left(500 \mathrm{MHz}, \mathrm{D}_{2} \mathrm{O}, 80^{\circ} \mathrm{C}\right)$ : $\delta 5.91(\mathrm{~s},=\mathrm{CH}, 1 \mathrm{H}), 6.71(\mathrm{~s}$, aromatic, $2 \mathrm{H}), 7.61(\mathrm{~s}$, aromatic, 2H). Anal. Calcd for $\left(\mathrm{C}_{8} \mathrm{H}_{6} \mathrm{O}_{3} \mathrm{~S} \cdot 13 / 5 \mathrm{H}_{2} \mathrm{O}\right)_{\mathrm{n}}$ : C, 41.95; H, 4.93. Found: C, 41.98; H, 4.76.

\section{Instruments}

NMR spectra were measured on a Varian VXR$500 \mathrm{~S}\left(500 \mathrm{MHz}\right.$ for $\left.{ }^{1} \mathrm{H}\right)$ spectrometer in $\mathrm{D}_{2} \mathrm{O}$ using acetone as the internal standard. IR spectra were recorded using a Jasco Fourier Transform IR-620 spectrophotometer (Jasco, Hachioji, Japan). Absorption and CD spectra were taken on a Jasco V-570 spectrophotometer and a Jasco J-725 spectropolarimeter, respectively, in a 1.0 or $10 \mathrm{~mm}$ quartz cell. The concentration of poly-1 was calculated based on the monomer units, and was corrected using the $\varepsilon$ (molar absorptivity) of poly-1 $\left(\varepsilon_{400}=2840 \mathrm{~cm}^{-1} \mathrm{M}^{-1}\right)$ in DMSO. SEC was performed using a Jasco PU-980 liquid chromatograph equipped with a UV-visible $\left(254 \mathrm{~nm}\right.$; Jasco UV-970) detector at $40^{\circ} \mathrm{C}$. A Tosoh TSKgel SUPER AWM-H column $(15 \mathrm{~cm})$ was connected and water-acetonitrile $(4 / 1, \mathrm{v} / \mathrm{v})$ containing sodium nitrate $(0.16 \mathrm{M})$ was used as the eluent at a flow rate of $0.5 \mathrm{~mL} / \mathrm{min}$. The molecular weight calibration curve was obtained with poly(ethylene oxide) and poly(ethylene glycol) standards (Tosoh).

\section{Measurements}

A typical experimental procedure is described below. Stock solutions of poly-1 $(2 \mathrm{mg} / \mathrm{mL}, 10.9 \mathrm{mM})$, $(R)-2(1.09 \mathrm{M})$, and $\mathrm{TosOH}(1.09 \mathrm{M})$ in DMSO were prepared. A $500 \mu \mathrm{L}$ aliquot of the stock solution of poly-1 was transferred to a vessel equipped with a screwcap using a micropipette (Mettler-Toledo $\mathrm{GmbH}$, Switzerland). To the vessel was added $250 \mu \mathrm{L}$ aliquots of the stock solutions of $(R)-2$ and $\mathrm{TosOH}$ $([(R)-2] /[$ poly-1 $]=50, \quad[\mathrm{TosOH}] /[(R)-2]=1) \quad$ and the $\mathrm{CD}$ and absorption spectra were measured.

Memory of Macromolecular Helicity: SEC Fractionation of Induced Helical Poly-1

A typical experimental procedure is described be- 
low. Stock solutions of poly-1 $(2 \mathrm{mg} / \mathrm{mL}, 10.9 \mathrm{mM})$, $(1 R, 2 S)-8(109 \mathrm{mM})$, and TosOH $(152 \mathrm{mM})$ in DMSO were prepared. A $500 \mu \mathrm{L}$ aliquot of the sock solution of poly-1 was transferred to a vessel equipped with a screwcap, and to this were added $250 \mu \mathrm{L}$ aliquots of the stock solutions of $(1 R, 2 S)-\mathbf{8}$ and TosOH $([(1 R, 2 S)-8] /[$ poly-1] $=5, \quad[$ TosOH $] /[$ poly-1 $]=7)$. The initial $\mathrm{CD}$ and absorption spectra were taken using a $1.0 \mathrm{~cm}$ quartz cell. SEC fractionation was performed using a Jasco PU-980 liquid chromatograph equipped with a UV (260 nm; Jasco UV-970) detector. A Shodex KF-806L SEC column $(30 \mathrm{~cm})$ was connected, and $0.3 \mathrm{M}$ of $\mathbf{1 5}$ in DMSO was used as the mobile phase at a flow rate of $1.0 \mathrm{~mL} / \mathrm{min}$. Before SEC fractionation, a $400 \mu \mathrm{L}$ aliquot of the poly-1$(1 R, 2 S)-\mathbf{8}$ complex solution was transferred to a vessel equipped with a screwcap, and to this was added $7.4 \mu \mathrm{L}$ of $15([15] /[$ poly-1] $=50)$. The $\mathrm{CD}$ and absorption spectra of the solution before SEC fractionation were measured in a 1-mm quartz cell. One hundred microliter of the solution of the poly-1$(1 R, 2 S)-\mathbf{8}$ complex with excess $\mathbf{1 5}$ was injected to the SEC system. The poly-1 complexed with 15, $\mathrm{TosOH}$, and $(1 R, 2 S)-\mathbf{8}$ were separately eluted and the poly-1 fraction was collected. The CD and absorption spectra of the fractionated poly-1 were measured in a $10.0 \mathrm{~mm}$ quartz cell. The recovery of $(1 R, 2 S)-\mathbf{8}$ was estimated from the peak area of the SEC chart detected by UV $(260 \mathrm{~nm})$ on the basis of the calibration curve, which was obtained from standard solutions of $(1 R, 2 S)-\mathbf{8}$ with TosOH. The standard solutions of $(1 R, 2 S)-\mathbf{8}$ with $\mathrm{TosOH}$ were prepared as follows. Stock solutions of $(1 R, 2 S)-\mathbf{8}(109 \mathrm{mM})$ and $\mathrm{TosOH}$ $(152 \mathrm{mM})$ in DMSO were prepared. Aliquots 150 , $200,250,300,350 \mu \mathrm{L}$ of the stock solution of $(1 R, 2 S)$ 8 were transferred to five $1-\mathrm{mL}$ flasks equipped with stopcocks using a micropipette. To these flasks was added $250 \mu \mathrm{L}$ of the stock solution of TosOH, the resulting solutions were diluted with DMSO to the $\operatorname{mark}([(1 R, 2 S)-8]=16.4,21.9,27.4,32.8,38.3 \mathrm{mM})$. The five standard solutions of $(1 R, 2 S)-8$ with $\mathrm{TosOH}$ were then injected to the SEC system and the calibration curve was obtained by plotting the peak area due to $(1 R, 2 S)-\mathbf{8}$ in the SEC charts detected by UV $(260 \mathrm{~nm})$ against the $(1 R, 2 S)-8$ concentrations of the standard solutions.

\section{RESULTS AND DISCUSSION}

\section{Helicity Induction in Poly-1 with Chiral Amines}

Figure 2A shows the typical $\mathrm{CD}$ and absorption spectra of poly-1 in the presence of $(R)$ - and $(S)$-2 $([2] /[$ poly-1] $=50)$ in DMSO. The complexes exhibited mirror images of the split-type ICDs in the UVvisible region of the polymer main chain due to the
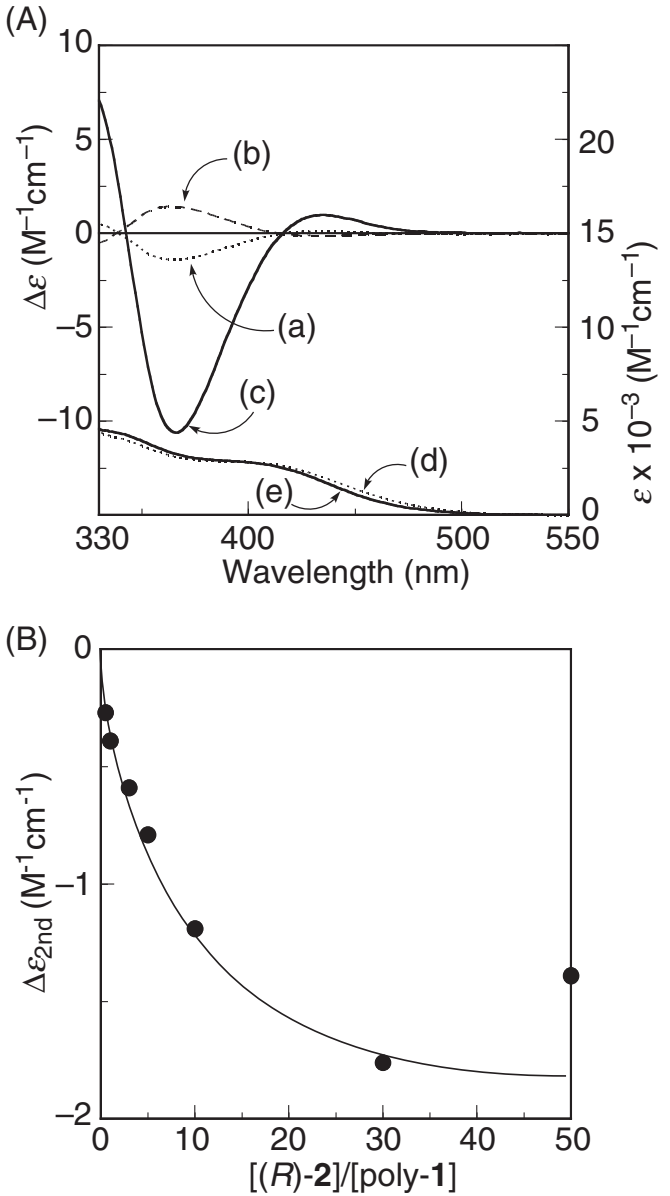

Figure 2. (A) CD spectra of poly-1 $(1.0 \mathrm{mg} / \mathrm{mL})$ with $(R)$ $(\mathrm{a}, \mathrm{c})$ and $(S)-2(\mathrm{~b})([2] /[$ poly-1] $=50)$ in the absence $(\mathrm{a}, \mathrm{b})$ and presence $([\mathrm{TosOH}] /[[$ poly-1 $]=50)$ of $\mathrm{TosOH}(\mathrm{c})$ in DMSO at ambient temperature $\left(24-26^{\circ} \mathrm{C}\right)$. Absorption spectra of poly-1 with $(R)-2$ in the absence (d) and presence of TosOH (e) in DMSO at ambient temperature $\left(24-26^{\circ} \mathrm{C}\right)$ are also shown. (B) Changes in the ICD intensity $\left(\Delta \varepsilon_{2 n d}\right)$ of poly-1 $(1.0 \mathrm{mg} / \mathrm{mL})$ versus the concentration of $(R)-2$ in DMSO at ambient temperature $\left(24-26^{\circ} \mathrm{C}\right)$.

formation of a predominantly one-handed helical conformation. The CD titration using $(R)-2$ showed that the magnitude of the ICD gradually increased with an increase in the concentration of $(R)-\mathbf{2}$ and reached an almost constant value in the presence of about 30 equiv. of $(R)-2$ (Figure 2B). However, the ICD intensity slightly decreased with a further increase in the concentration of $(R)-2$. The ICD intensity of the poly-1- $(R)-2$ complex corresponding to an excess of a single-handed helix of the polymer backbone was very weak compared with those of PCPA, PPPA, and PEPPA induced by $(R)-2$; the second Cotton intensities $\left(\Delta \varepsilon_{2 n d}\right)$ of the complexes of PCPA, PPPA, and PEPPA with $(R)-2$ in DMSO were $-9.27,+11.2$, and $+16.9([(R)-2] /[\mathrm{PCPA}$ or PPPA $]=50$ and $[(R)$ 2] $/[\mathrm{PEPPA}]=10)$, respectively. ${ }^{27,31}$

In the acid-base complexation of poly-1 with chiral amines in DMSO, there exist equilibria between the 


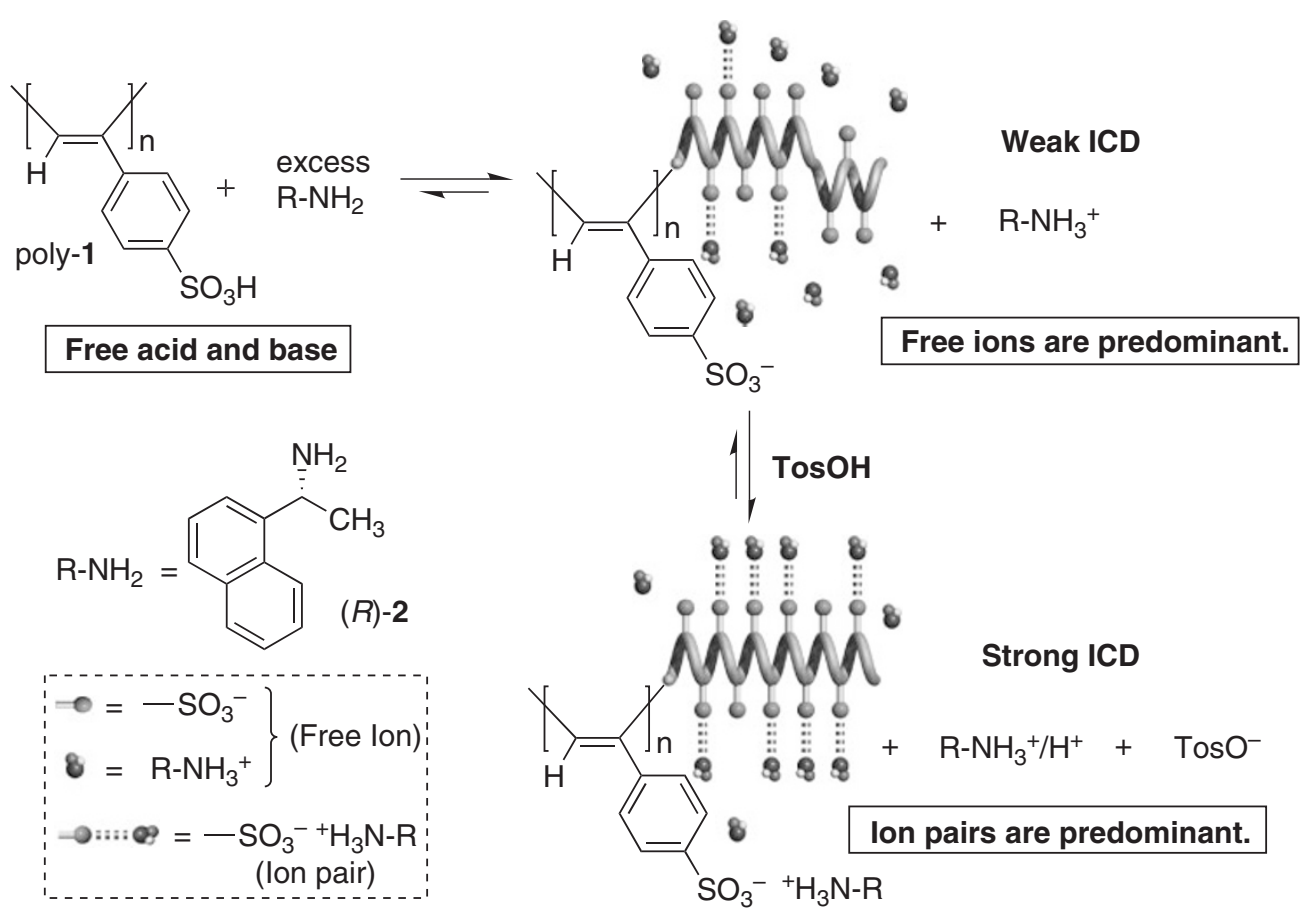

Scheme 1. Schematic illustration of one-handed helicity induction in poly-1 upon complexation with an optically active amine $((R)-\mathbf{2})$ in the presence of an achiral strong acid (TosOH).

free acid and base, the ion pair, and the free ions as shown in Scheme 1. ${ }^{27,36,44-46}$ Among these three species, the ion pair formation is essential for the helicity induction in one-handedness excess, resulting in the appearance of an intense ICD in the polymer backbone as reported for PCPA with chiral amines. ${ }^{36}$ The pendant sulfonic acid of poly-1 is more acidic than the carboxylic acid of the PCPA and phosphonic acid of the PPPA and PEPPA. The $p$ Ka values of benzoic acid, phenylphosphonic acid, phenylphosphonic acid monomethyl ester, and phenylsulfonic acid as model compounds of PCPA, PPPA, PEPPA, and poly1 are $4.19,{ }^{47} 1.83\left(p \mathrm{Ka}_{1}\right)$ and $7.07\left(p \mathrm{Ka}_{2}\right),{ }^{48} 2.97,{ }^{49}$ and $0.7,{ }^{47}$ respectively. Therefore, in the poly-1-chiral amine complexation, the free ions (sulfonate and ammonium ions) should be predominant in DMSO, ${ }^{50-52}$ and the dissociated free ions derived from a chiral amine $(R)-2$ could not effectively interact with poly-1, thus showing a very weak ICD ( $a$ and $b$ in Figure 2A).

However, as previously reported, ${ }^{36}$ the addition of a common salt of $(R)-\mathbf{2}$, such as $(R)-\mathbf{2} \cdot \mathrm{TosOH}$, is expected to suppress the dissociation of the ion pair into the free ions, resulting in an increase in the ICD intensity (Scheme 1). TosOH was then added to the poly1- $(R)-2$ complex $([(R)-2] /[$ polymer $]=50)$ in DMSO showing a weak ICD $\left(\Delta \varepsilon_{2 \text { nd }}=-1.4\right)$. As expected, the ICD intensity dramatically increased with the increasing amount of the $\mathrm{TosOH}$ (Figure 3) and reached a maximum value $\left(\Delta \varepsilon_{2 \text { nd }}=-10.6\right)$ at around $[\mathrm{TosOH}] /[(R)-2]=1$ (c in Figure $2 \mathrm{~A})$. The further

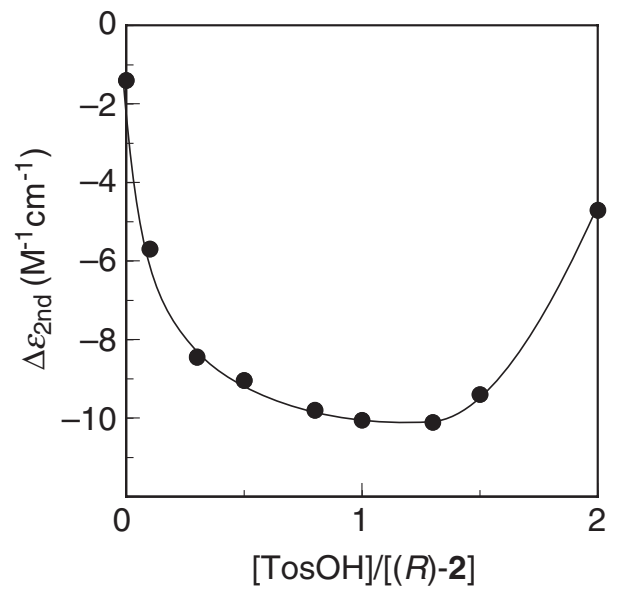

Figure 3. Changes in the ICD intensity $\left(\Delta \varepsilon_{2 n d}\right)$ of poly-1 $(1.0 \mathrm{mg} / \mathrm{mL})$ with $(R)-2 \quad([(R)-\mathbf{2}] /[$ poly-1] $=50)$ versus the concentration of $\mathrm{TosOH}$ in DMSO at ambient temperature $\left(24-26^{\circ} \mathrm{C}\right)$.

addition of TosOH $([\mathrm{Tos} \mathrm{OH}] /[(R)-2] \geq 1.5)$ resulted in a decrease in the ICD intensity, probably because the excess free $\mathrm{Tos} O \mathrm{H}$ may prevent the interaction between poly-1 and $(R)-\mathbf{2}$.

Poly-1 responded to other chiral amines and amino alcohols (Figure 4) and the complexes exhibited similar ICDs in their patterns (Table I). In most cases, the ICD magnitudes increased in the presence of $\mathrm{TosOH}$ $([\mathrm{Tos} \mathrm{OH}] /[$ amines $]=1)$, but their increments were significantly dependent on the structures of the chiral amines and amino alcohols. In particular, the change was remarkable for chiral amines with a bulky sub- 
<smiles>CC(N)c1cccc2ccccc12</smiles>

(R)-2<smiles>CC(N)c1cccc2ccccc12</smiles>

(S)-2<smiles>CC(N)c1ccccc1</smiles>

$(R)-3$<smiles>CC(N)C1CCCCC1</smiles>

(R)-4<smiles>CCC(C)N</smiles>

(S)-5<smiles>C[C](N)CO</smiles>

(S)-9<smiles>N[C@@H](CO)Cc1ccccc1</smiles>

(S)-6<smiles>N[C@@H](CO)c1ccccc1</smiles>

(R)-7<smiles>C[C@H](N)[C@@H](O)c1ccccc1</smiles>

$(1 R, 2 S)-8$<smiles>N[C@H]1c2ccccc2CC1O</smiles>

(1R,2S)-11

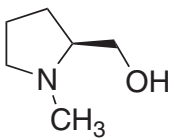

(S) -12

Figure 4. Structures of optically active amines (2-5) and amino alcohols (6-12).

Table I. Difference in exciton coefficient of the second Cotton $\left(\Delta \varepsilon_{2 n d}\right)$ for the complexes of poly-1 with chiral amines and amino alcohols in DMSO in the presence and absence of $\mathrm{TosOH}^{\mathrm{a}}$

\begin{tabular}{|c|c|c|c|c|}
\hline \multirow[b]{3}{*}{ Amines } & \multicolumn{4}{|c|}{ Second Cotton $\left[\lambda(\mathrm{nm})\right.$ and $\left.\Delta \varepsilon_{2 \mathrm{nd}}\left(\mathrm{M}^{-1} \mathrm{~cm}^{-1}\right)\right]$} \\
\hline & \multicolumn{2}{|c|}{ Before addition of $\mathrm{Tos} O \mathrm{H}$} & \multicolumn{2}{|c|}{ After addition of TosOH } \\
\hline & Sign & $\Delta \varepsilon_{2 \text { nd }}(\lambda)$ & Sign & $\Delta \varepsilon_{2 \text { nd }}(\lambda)$ \\
\hline$(R)-2$ & - & $1.4(363)$ & - & $10.6(366)$ \\
\hline$(S)-2$ & + & $1.4(365)$ & + & $10.6(366)$ \\
\hline$(R)-\mathbf{3}$ & - & $3.8(366)$ & - & $12.5(366)$ \\
\hline$(R)-4$ & - & $4.1(367)$ & - & $6.9(367)$ \\
\hline$(S)-5$ & - & $4.7(365)$ & - & $4.9(365)$ \\
\hline$(S)-6$ & - & $7.0(366)$ & - & $8.8(366)$ \\
\hline$(R)-7$ & - & $3.1(368)$ & - & $5.8(368)$ \\
\hline$(1 R, 2 S)-\mathbf{8}$ & - & $9.9(365)$ & - & $11.4(366)$ \\
\hline$(1 S, 2 R)-\mathbf{8}$ & + & $10.8(366)$ & + & $11.4(366)$ \\
\hline$(S)-9$ & + & $0.8(368)$ & + & $0.6(369)$ \\
\hline$(S)-\mathbf{1 0}$ & + & $4.0(365)$ & + & $6.2(366)$ \\
\hline$(1 R, 2 S)-\mathbf{1 1}$ & - & $4.5(366)$ & - & $8.5(366)$ \\
\hline$(S)-12$ & - & 0.7 (363) & - & $1.4(366)$ \\
\hline
\end{tabular}

${ }^{\mathrm{a}}$ All spectra were measured at ambient temperature ( $\mathrm{ca}$. $24-26^{\circ} \mathrm{C}$ ) with a poly-1 concentration of $1.0 \mathrm{mg} / \mathrm{mL}$. The molar ratios of amines and $\mathrm{TosOH}$ to monomer units of poly-1 are 50 .

stituent at the $\alpha$-position of the amino group (2-4, 7, and 11) by the addition of $\mathrm{TosOH}$, whereas the less bulky 5 and 9 showed almost no change in their ICDs with $\mathrm{Tos} \mathrm{OH}$. In addition, the bulky aromatic amino alcohols $(\mathbf{6}, \mathbf{8}$, and $\mathbf{1 1})$ tended to show relatively intense ICDs in the absence and presence of TosOH (Table I). The cooperative hydrogen bond formation of the hydroxy group with a sulfonic acid residue of poly-1 as well as the acid-base interaction may play a role. As for the relationship between the induced Cotton effect signs for poly-1 and the absolute configurations of the amines and amino alcohols tested in this

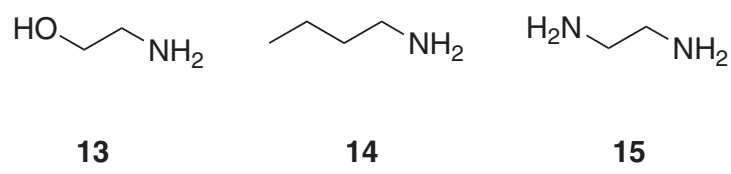

Figure 5. Structures of achiral amines (13-15).

study, there is no clear relation, although the primary amines (2-5) and amino alcohols (6-11) of the same configuration gave the same Cotton effect signs for PCPA, ${ }^{26,27}$ PPPA, $^{31}$ and PEPPA $^{31}$ in DMSO except for 10 for PPPA.

Memory of the Macromolecular Helicity of Poly-1

As described above, the induced macromolecular helicity in PCPA, PPPA, and PEPPA upon complexation with the optically active amines, such as $(R)-2$, can be "memorized" by replacing $(R)-2$ with various achiral amines and amino alcohols for PCPA $^{35-38}$ and diamines for PPPA and PEPPA ${ }^{31}$ in DMSO. We applied this methodology to poly-1 and investigated if a similar macromolecular helicity memory could be possible for the analogous stereoregular poly-1 bearing a more acidic sulfonic acid residue as the pendant.

The chiral amino alcohol $\mathbf{8}$ was selected as a helix inducer because a relatively small amount of $\mathbf{8}$ ([8]/ [poly-1] $=5$ ) was enough to induce a greater excess of a single-handed helix regardless of the presence of the common salt, while a large excess amount of $(R)-2([8] /[$ poly-1] $>30)$ together with the common salt was required to produce as intense an ICD as that with 8. As achiral amines for the memory experiments, 2-aminoethanol (13), n-butylamine (14), and ethylenediamine (15) (Figure 5) were selected because these were good chaperoning molecules to as- 
sist in the memory of the macromolecular helicity of PCPA (13 and 14) ${ }^{35-38}$ and PPPA or PEPPA (15). ${ }^{31}$ First, we added an excess amount of achiral amines $(\mathbf{1 3}-\mathbf{1 5})([\mathbf{1 3}-\mathbf{1 5}] /[$ poly-1 $]=50)$ to the poly-1$(1 R, 2 S)-8$ complex $([(1 R, 2 S)-8] /[$ poly-1] $=5)$ in DMSO in order to check if the macromolecular helicity of the poly- $\mathbf{1}$ induced by $(1 R, 2 S)-\mathbf{8}$ could be retained after $(1 R, 2 S)-\mathbf{8}$ is replaced by the achiral 13-15. The ICD of the poly-1-(1R,2S)-8 complex $\left(\Delta \varepsilon_{2 \text { nd }}=-8.2\right)$ instantly disappeared after the addition of the achiral 13-15, suggesting that the helicity of poly-1 induced by $(1 R, 2 S)-\mathbf{8}$ could not be maintained at all by 13-15. Previously, we reported that PCPA and chiral amines could be complexed more efficiently through ion pairing in the presence of the common salts of the chiral amines, and the memory efficiency significantly improved when the replacement of the chiral amine with achiral amines was performed in the presence of the common salts of the chiral amines. ${ }^{36}$ We then carried out the addition experiments described above in the presence of the common salt, $(1 R, 2 S)-\mathbf{8} \cdot \mathrm{Tos} O \mathrm{H}$. The poly-1- $(1 R, 2 S)-\mathbf{8}$ complex containing TosOH $([(1 R, 2 S)-8] /[$ polymer]/ $[\mathrm{TosOH}]=5 / 1 / 5)$ in DMSO showing a slightly more intense ICD $\left(\Delta \varepsilon_{2 \text { nd }}=-9.7\right)$ than that in the absence of $\mathrm{TosOH}$ were prepared. An apparent ICD signal $\left(\Delta \varepsilon_{2 \text { nd }}=-3.3\right)$ was still observed even after the addition of an excess amount of $\mathbf{1 5}([\mathbf{1 5}] /[$ poly-1] $=50)$, while the addition of $\mathbf{1 3}$ and $\mathbf{1 4}$ resulted in the complete disappearance of the ICD. These results suggest that the macromolecular helical chirality of poly-1 induced by $(1 R, 2 S)-\mathbf{8}$ in the presence of the common salt would be maintained by the diamine $\mathbf{1 5}$, although achiral monoamines $\mathbf{1 3}$ and $\mathbf{1 4}$ were not effective for the memory of the induced macromolecular helicity of poly-1. A similar structural effect of the achiral diamines was observed for the memory of the induced helical PPPA and PEPPA. ${ }^{31} \mathrm{We}$ then investigated the effect of the concentration of TosOH on the efficiency of the macromolecular helicity memory. The best result was obtained when the molar ratio of $\mathrm{Tos} \mathrm{OH}$ to the monomeric units of poly-1 was around $7-8$, where the $\Delta \varepsilon_{2 \text { nd }}$ value of the poly-1 after the addition of the excess amount of $\mathbf{1 5}$ was -5.4 (Figure 6). In order to obtain concrete evidence for the macromolecular helicity memory, we isolated the poly-1 from the poly-1- $(1 R, 2 S)-\mathbf{8}$ complex with TosOH and excess $15([$ poly-1] $] /[(1 R, 2 S)-8] /[$ TosOH $] /[\mathbf{1 5}]=1 / 5 /$ $7 / 50$ ) by SEC using a DMSO solution containing $0.3 \mathrm{M} 15$ as the mobile phase in a similar way as previously reported for the memory experiments of PCPA, PPPA, and PEPPA. ${ }^{31,35-38}$ The poly-1 eluted first, followed by the $\mathrm{TosOH}$, then $(1 R, 2 S)-\mathbf{8}$, and they were completely separated. The poly-1 fraction was collected and subjected to CD and absorption meas-

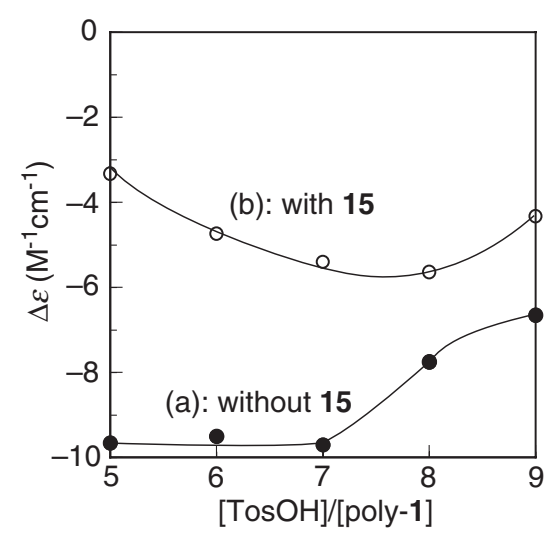

Figure 6. Dependence of the ICD intensity ( $\left.\Delta \varepsilon_{2 \text { nd }}\right)$ of poly-1 $(1.0 \mathrm{mg} / \mathrm{mL})$ with $(1 R, 2 S)-\mathbf{8}$ in the absence (a) and presence of $\mathbf{1 5}$ $([15] /[$ poly-1] $=50)$ (b) against the concentration of TosOH in DMSO at rt. The molar ratio of $(1 R, 2 S)-\mathbf{8}$ to monomer units of poly-1 is 5 .

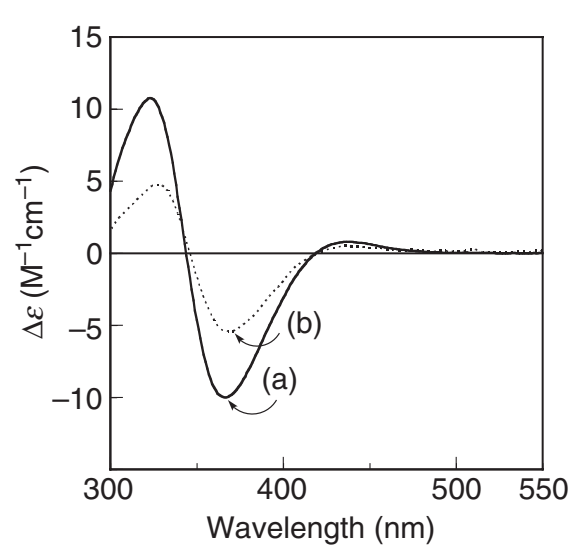

Figure 7. CD spectra of poly-1 with $(1 R, 2 S)-\mathbf{8}$ in the presence of $\mathrm{TosOH}([(1 R, 2 S)-8] /[$ poly-1] $] /[\mathrm{TosOH}]=5 / 1 / 7])$ (a) and the isolated poly-1 by SEC fractionation using a DMSO solution of $15(0.3 \mathrm{M})$ as the mobile phase (b), in DMSO at ambient temperature $\left(24-26^{\circ} \mathrm{C}\right)$.

urements. On the basis of the calibration curve obtained from the standard solutions of $(1 R, 2 S)-\mathbf{8}$ with $\mathrm{TosOH}$, more than $99 \%$ of the $(1 R, 2 S)-\mathbf{8}$ was removed from the poly-1. On the basis of the ratio of the ICD intensities of the second Cotton effect $\left(\Delta \varepsilon_{2 \text { nd }}\right)$ of the poly-1 before (a) and after (b) the SEC fractionation, the memory efficiency was estimated to be $53 \%$ (Figure 7).

The macromolecular helicity memory of poly-1 assisted by the interaction with an achiral diamine $\mathbf{1 5}$ lasted for over six months as observed for the helical PCPA, PPPA, and PEPPA with a helicity memory after the SEC fractionation, ${ }^{31,35-38}$ but the memory gradually declined with time at ambient temperature (20$25^{\circ} \mathrm{C}$ ) and the ICD intensity of the fractionated poly-1 showed a decrease of about $20 \%$ at room temperature after $185 \mathrm{~d}$. The stability of the memory was highly 
dependent on the concentration of the salts and the decreasing rate was accelerated in the presence of the common salts; the ICD completely disappeared after $12 \mathrm{~h}$ in the presence of $\mathbf{1 5} \cdot \mathrm{TosOH}([\mathbf{1 5} \cdot \mathrm{Tos} \mathrm{OH}]=$ $2.5 \mathrm{mM})$. As already described, the dissociation of the ion pairs into free ions is suppressed in the presence of the common salt. Therefore, this result suggests that the intramolecular electrostatic repulsions between the neighboring sulfonate groups play an important role in the maintenance of the helical chirality of poly-1 in accordance with the previous results. ${ }^{36}$ As described above, achiral monoamines, such as $\mathbf{1 3}$ and 14, were not effective for the memory of the induced helical structures of poly-1, and the achiral diamines are necessary for the memory effect in poly-1. Therefore, the bidentate ion-paired electrostatic interactions between the neighboring sulfonate groups of the polymers and the diammonium moieties are also essential for the memory in poly-1 as well as in PPPA and PEPPA. ${ }^{31}$

\section{CONCLUSION}

In summary, we have found that a poly(phenylacetylene) derivative bearing a sulfonic acid residue as the pendant can form a predominantly one-handed helical conformation upon complexation with various chiral amines and amino alcohols through noncovalent acid-base interactions in DMSO. Moreover, the induced macromolecular helicity of poly-1 could be memorized by replacement of a chiral amine with an achiral diamine. In sharp contrast to the similar helicity induction and memory of poly(phenylacetylene)s bearing carboxy and phosphonic acid residues as the pendants, the presence of the common salt of the chiral amines was required for the effective helicity induction and the memory of poly-1 in DMSO due to the highly acidic sulfonate groups of poly-1 which favorably dissociate into free ions in DMSO in the absence of common salts. The present results indicate that a similar helicity induction and subsequent memory may be possible for other dynamic helical polymers ${ }^{53-61}$ including polyacetylenes ${ }^{62-69}$ bearing acidic or basic functional groups by the precise control of their ion pair formation and dissociation into free ions in solutions, respectively.

Acknowledgment. This work was partially supported by Grant-in-Aid for Scientific Research from Japan Society for the Promotion of Science and the Ministry of Education, Culture, Sports, Science, and Technology, Japan and the 21st Century COE Program "Nature-Guided Materials Processing" of the Ministry of Education, Culture, Sports, Science and Technology.

\section{REFERENCES}

1. Y. Okamoto and T. Nakano, Chem. Rev., 94, 349 (1994).

2. R. J. M. Nolte, Chem. Soc. Rev., 23, 11 (1994).

3. M. M. Green, N. C. Peterson, T. Sato, A. Teramoto, R. Cook, and S. Lifson, Science, 268, 1860 (1995).

4. L. Pu, Acta Polym., 48, 116 (1997).

5. M. Srinivasarao, Curr. Opin. Colloid Interface Sci., 4, 370 (1999).

6. M. M. Green, J.-W. Park, T. Sato, A. Teramoto, S. Lifson, R. L. B. Selinger, and J. V. Selinger, Angew. Chem., Int. Ed., 38, 3138 (1999).

7. T. Nakano and Y. Okamoto, Chem. Rev., 101, 4013 (2001).

8. J. J. L. M. Cornelissen, A. E. Rowan, R. J. M. Nolte, and N. A. J. M. Sommerdijk, Chem. Rev., 101, 4039 (2001).

9. M. Fujiki, Macromol. Rapid Commun., 22, 539 (2001).

10. R. Nomura, H. Nakako, and T. Masuda, J. Mol. Catal. A: Chem., 190, 197 (2002).

11. M. Fujiki, J. R. Koe, K. Terao, T. Sato, A. Teramoto, and J. Watanabe, Polym. J., 35, 297 (2003).

12. E. Yashima, K. Maeda, and T. Nishimura, Chem. Eur. J., 10, 42 (2004).

13. J. W. Lockman, N. M. Paul, and J. R. Parquette, Prog. Polym. Sci., 30, 423 (2005).

14. S. H. Gellman, Acc. Chem. Res., 31, 173 (1998).

15. D. J. Hill, M. J. Mio, R. B. Prince, T. S. Hughes, and J. S. Moore, Chem. Rev., 101, 3893 (2001).

16. R. P. Cheng, S. H. Gellman, and W. F. DeGrado, Chem. Rev., 101, 3219 (2001).

17. A. R. Sanford and B. Gong, Curr. Org. Chem., 7, 1649 (2003).

18. I. Huc, Eur. J. Org. Chem., 17 (2004).

19. A. E. Rowan and R. J. M. Nolte, Angew. Chem., Int. Ed., 37, 63 (1998).

20. L. Brunsveld, B. J. B. Folmer, E. W. Meijer, and R. P. Sijbesma, Chem. Rev., 101, 4071 (2001).

21. J. A. A. W. Elemans, A. E. Rowan, and R. J. M. Nolte, J. Mater. Chem., 13, 2661 (2003).

22. M. A. Mateos-Timoneda, M. Crego-Calama, and D. N. Reinhoudt, Chem. Soc. Rev., 33, 363 (2004).

23. J. Zhang, M. T. Albelda, Y. Liu, and J. W. Canary, Chirality, 17, 404 (2005).

24. F. J. M. Hoeben, P. Jonkheijm, E. W. Meijer, and A. P. H. J. Schenning, Chem. Rev., 105, 1491 (2005).

25. H. M. Keizer and R. P. Sijbesma, Chem. Soc. Rev., 34, 226 (2005).

26. E. Yashima, T. Matsushima, and Y. Okamoto, J. Am. Chem. Soc., 117, 11596 (1995).

27. E. Yashima, T. Matsushima, and Y. Okamoto, J. Am. Chem. Soc., 119, 6345 (1997).

28. M. A. Saito, K. Maeda, H. Onouchi, and E. Yashima, Macromolecules, 33, 4616 (2000).

29. H. Onouchi, T. Hasegawa, D. Kashiwagi, H. Ishiguro, K. Maeda, and E. Yashima, Macromolecules, 38, 8625 (2005).

30. Y. Kamikawa, T. Kato, H. Onouchi, D. Kashiwagi, K. Maeda, and E. Yashima, J. Polym. Sci., Part A: Polym. Chem., 42, 4580 (2004).

31. H. Onouchi, D. Kashiwagi, K. Hayashi, K. Maeda, and 
E. Yashima, Macromolecules, 37, 5495 (2004).

32. H. Onouchi, K. Maeda, and E. Yashima, J. Am. Chem. Soc., 123, 7441 (2001).

33. T. Nishimura, K. Tsuchiya, S. Ohsawa, K. Maeda, E. Yashima, Y. Nakamura, and J. Nishimura, J. Am. Chem. Soc., 126, 11711 (2004).

34. H. Onouchi, T. Miyagawa, A. Furuko, K. Maeda, and E. Yashima, J. Am. Chem. Soc., 127, 2960 (2005).

35. E. Yashima, K. Maeda, and Y. Okamoto, Nature, 399, 449 (1999).

36. K. Maeda, K. Morino, Y. Okamoto, T. Sato, and E. Yashima, J. Am. Chem. Soc., 126, 4329 (2004).

37. K. Morino, N. Watase, K. Maeda, and E. Yashima, Chem. Eur. J., 10, 4703 (2004).

38. T. Hasegawa, K. Morino, Y. Tanaka, H. Katagiri, Y. Furusho, and E. Yashima, Macromolecules, 39, 482 (2006).

39. C. I. Simionescu, V. Percec, and S. Dumitrescu, J. Polym. Sci., Part A: Polym. Chem., 15, 2497 (1997).

40. C. I. Simionescu and V. Percec, Prog. Polym. Sci., 8, 133 (1982).

41. A. Furlani, C. Napoletano, M. V. Russo, and W. J. Feast, Polym. Bull., 16, 311 (1986).

42. S. Matsunami, T. Kakuchi, and F. Ishii, Macromolecules, 30, 1074 (1997).

43. Y. Kishimoto, P. Eckerle, T. Miyatake, M. Kainosho, A. Ono, T. Ikariya, and R. Noyori, J. Am. Chem. Soc., 121, 12035 (1999).

44. S. P. Zingg, E. M. Arnett, A. T. McPhail, A. A. Bothner-By, and W. R. Gilkerson, J. Am. Chem. Soc., 110, 1565 (1988).

45. K. Izutsu, "Acid-Base Dissociation Constants in Dipolar Aprotic Solvents," Blackewll, Oxford, 1990.

46. C. Reichardt, "Solvents and Solvent Effects in Organic Chemistry," VCH, Weinheim, Germany, 1990.

47. S. H. Pine, "Organic Chemistry," 5th ed., McGraw Hill, New York, 1987, p 99.

48. H. H. Jaffé, L. D. Freedman, and G. O. Doak, J. Am. Chem. Soc., 75, 2209 (1953).

49. H. Christol, M. Levy, and C. Marty, J. Organomet. Chem., 12, 459 (1968).

50. In DMSO, TosOH is almost completely dissociated even in the absence of a base and the sulfonate ions predominantly exist as solvent-separated ion pairs or free ions. a) $\mathrm{K}$.
Manabe, K. Okamura, T. Date, and K. Koga, J. Am. Chem. Soc., 114, 6940 (1992). b) K. Manabe, K. Okamura, T. Date, and K. Koga, J. Org. Chem., 58, 6692 (1993).

51. Z. H. Ping, Q. T. Nguyen, S. M. Chen, and Y. D. Ding, J. Membr. Sci., 195, 23 (2002).

52. M. Hara, A. H. Lee, and J. W. Rutgers, J. Polym. Sci., Part B: Polym. Phys., 25, 1407 (1987).

53. D. S. Schlitzer and B. M. Novak, J. Am. Chem. Soc., 120, 2196 (1998).

54. I. D. Norris, L. A. P. Kane-Maguire, and G. G. Wallace, Macromolecules, 31, 6529 (1998).

55. K. Maeda, N. Yamamoto, and Y. Okamoto, Macromolecules, 31, 5924 (1998).

56. E. Yashima, K. Maeda, and T. Yamanaka, J. Am. Chem. Soc., 122, 7813 (2000).

57. M. Ishikawa, K. Maeda, and E. Yashima, J. Am. Chem. Soc., 124, 7448 (2002).

58. J. Tabei, R. Nomura, F. Sanda, and T. Masuda, Macromolecules, 36, 8603 (2003).

59. Y. Inai, N. Ousaka, and T. Okabe, J. Am. Chem. Soc., 125, 8151 (2003).

60. R. Sakai, T. Satoh, R. Kakuchi, H. Kaga, and T. Kakuchi, Macromolecules, 37, 3996 (2004).

61. R. Kakuchi, R. Sakai, I. Otsuka, T. Satoh, H. Kaga, and T. Kakuchi, Macromolecules, 38, 9441 (2005).

62. E. Yashima, H. Goto, and Y. Okamoto, Polym. J., 30, 69 (1998).

63. K. Maeda, H. Goto, and E. Yashima, Macromolecules, 34, 1160 (2001).

64. T. Miyagawa, A. Furuko, K. Maeda, H. Katagiri, Y. Furusho, and E. Yashima, J. Am. Chem. Soc., 127, 5018 (2005).

65. E. Yashima, Y. Maeda, and Y. Okamoto, Chem. Lett., 25, 955 (1996).

66. E. Yashima, Y. Maeda, T. Matsushima, and Y. Okamoto, Chirality, 9, 593 (1997).

67. K. Maeda, S. Okada, E. Yashima, and Y. Okamoto, J. Polym. Sci., Part A: Polym. Chem., 39, 3180 (2001).

68. K. Maeda, Y. Takeyama, K. Sakajiri, and E. Yashima, J. Am. Chem. Soc., 126, 16284 (2004).

69. K. Nagai, K. Maeda, Y. Takeyama, K. Sakajiri, and E. Yashima, Macromolecules, 38, 5444 (2005). 